ENCODING VALUES AND PRACTICES IN ETHICAL JEWELLERY PURCHASING: A CASE HISTORY OF ITALIAN ETHICAL LUXURY CONSUMPTION

\author{
by \\ Linda Armano \\ University of British Columbia Okanagan \\ and \\ Annamma Joy* \\ University of British Columbia Okanagan
}

Linda Armano is a Marie Curie Global Fellow at the Faculty of Management at the University of British Columbia Okanagan and at the Università Ca’ Foscari Venezia, Venice, Italy. larmano@ubc.ca. Tel: 250-826-8429.

Annamma Joy is a Professor of Marketing on the Faculty of Management at the University of British Columbia Okanagan, 3333 University Way, Kelowna, BC Canada V1V 1V7, Tel: (250) 807-8606, annamma.joy@ubc.ca. The authors gratefully acknowledge receipt of a Social Sciences and Humanities Research Council grant \#

(*) Corresponding author

The authors acknowledge the receipt of a Marie Curie Fellowship to Dr. Linda Armano. 
ENCODING VALUES AND PRACTICES IN ETHICAL JEWELLERY

PURCHASING: A CASE HISTORY OF ITALIAN ETHICAL LUXURY CONSUMPTION

\begin{abstract}
The concept of ethical jewellery today includes certified Fair mined gold as well as conflict-free and ethically mined diamonds; consumption of such products is soaring in tandem with evolving consumer interest in ethical labour practices and sustainability. While previous studies investigate ethical jewellery consumption, the literature is silent on such consumption by Italian consumers. We aim to close this gap, through a case history of Italy's first and currently most popular ethical jewellery store, Gioielleria (Jewellery) Belloni in Milan. Through ethnographic interviews with the owner and a representative sample of his clientele, we illuminate an ethical jeweller's practices and values, contextualized in the socio-cultural traditions unique to Italy. We further examine how Italian ethical consumers interpret Canadian ethical diamonds and certified Fair mined gold during their purchasing experiences, vis-à-vis their perceptions of the Made in Italy brand. We employ Ethnopragmatic Theory (Duranti 2011) and the concept of Territorialisation (De Martino 2008) in our conceptual framework.
\end{abstract}

Keywords: Ethical jewellery consumption; Italian ethical jewellery consumers; conflict-free diamonds; Fair mined gold; Made in Italy brand; Ethnopragmatic Theory; Territorialisation 


\section{ENCODING VALUES AND PRACTICES IN ETHICAL JEWELLERY PURCHASING: A CASE HISTORY OF ITALIAN ETHICAL LUXURY CONSUMPTION}

\section{Introduction}

The concept of ethical jewellery today includes certified Fair mined gold, along with conflict-free and ethically mined diamonds. Consumption of ethical jewellery has soared in recent years, in tandem with rising consumer interest in fair labour practices and environmentally sound manufacturing. The issue of ethics in jewellery production has gained equal weight to sustainability; whether relating to global mining activities (Kjarsgaard and Levinson 2002), supply chain management (Okatei et al. 2017), or labour practices, ethics has risen to the forefront of consumer consciousness. Non-profit organisations, activist groups, and international governmental institutions have drawn consumer attention to ethics in jewellery manufacturing via campaigns addressing corporate social irresponsibility (Hilson 2008, 2015; Moraes et al. 2017), including lack of transparency, human rights abuses such as child labour, environmental degradation from mining, and the role of conflict diamonds in funding terrorism. These criticisms present fundamental challenges to the organisations of the global jewellery supply chain, as well as corporate governance (Muskawa 2014). Many scholars (Kapferer and MichautDenizeau 2013) note that most major mining companies and luxury groups have over the past twenty years embraced ethical and sustainability positions; Tiffany and De Beers have long cited social and environmental responsibility as intrinsic to their business models. Accordingly, 
consumer criteria for fine jewellery purchase decisions are now likely to include ethical business practices (Muskawa 2014), although research in this area remains scant (Moraes et al. 2017).

Most approaches to the issues of luxury consumption start from social theory and are often based on an ontological perspective of dualism between the individual consumer and the overall social structure. This dualism has been challenged by alternative sets of understandings of human action in context (Schatzki 1997; Reckwitz 2002), which traverse individuals and structures, and assume a societal framework comprising social practices produced and reproduced across time and space (Giddens 1984). These different approaches can be inserted in the common category described as practice theories (Moraes et al. 2017). While practice theories are employed in a diverse range of topics related to consumption and marketing (Echeverri and Skålén 2011), their primary application relates to research on consumption (Harvey et al. 2001; Warde 2005; Arsel and Bean 2013) and studies on behaviours modified to reflect a commitment to sustainability (Røpke 2009; Shove and Walker 2010; Evans-Lacko et al. 2012; Rettie et al. 2012).

While economic models assume that human actions are dependent on individual objectives, and other social theories tend to see actions as a form of compromise between social norms and the need for some degree of consensus, practice theories seek to highlight action through symbolic processes of interconnected meanings (Reckwitz 2002).

The proliferation of approaches attempting to overtake the implicit dualism in the social science literature shares some commonalities whereby practice explanations are related to human activities, knowledge, meaning, language, social institutions, and historical transformations involved in the field of practice (Schatzki 2001). In many studies consumers are visualized as practitioners rather than authors of their own actions; thus, they can execute actions according to 
a shared social background of knowledge and understanding of normality, which in turn are interpreted subjectively (Evans-Lacko et al. 2012). This conception implies that different forms of consumption are embedded in the social underlayer and linked to individuals' judgments of what comprises normal actions (Shove and Walker 2010; Rettie et al. 2012).

Despite the significant corpus of works on consumption, no clear, unified practice theory approach exists in extant literature regarding ethical and sustainability issues in consumption studies, despite the urgent timeliness of understanding these issues (Fuentes and Martìnez-Jurado 2014); indeed, the very definition of such issues is unclear. For example, some investigations suggest that consumers' meanings do not consider the potentially negative impact of luxury consumption, since luxury products do not appear frequently in commodity consumption practices. Moreover, consumers may perceive such products as unaffordable, thus rendering the ethical issues related to such goods moot (Davies et al. 2012).

As suggested by Moraes et al. (2017), ethical issues in luxury consumption need new processes to understand how people incorporate materials, knowledge, and meanings in their ways of consuming. Moraes et al. suggest applying practice theories, not only to study routine purchases, but also to examine non-habitual practices such as ethical luxury consumption. Notably, they further propose linking norms and the consumption environment to consumers' behaviours. Via this approach, scholars aim to explore how these practices are learned and shared among consumers in their daily lives (Moraes et al. 2017: 532).

While previous studies investigate ethical jewellery consumption, the literature is silent on such consumption by Italian consumers. In the present study, following Moraes et al., we aim to close this gap, through the lens of a case history of Italy's first and primary ethical jewellery store, Gioielleria (Jewellery) Belloni in Milan. Through ethnographic interviews with owner 
Francesco Belloni and a representative sample of his clientele, we illuminate the specifics of an ethical jeweller's practices and values, contextualized in the socio-cultural traditions unique to Italy.

Rather than rely on a theory of social practices applied to studies of luxury consumption, we furnish a completely new conceptual framework, applying Ethnopragmatic Theory (Duranti 2011 and referred to hereafter as ET), which has heretofore never been applied in an analysis of luxury consumption. Through our methodology, we examine how Italian ethical consumers interpret Canadian ethical diamonds and certified Fair mined gold during their ethical purchasing experiences, including through comparisons with their perceptions of the Made in Italy brand. To deeply understand the overlapping consumption spaces of Canadian jewellery products on the one hand and their Made in Italy counterparts on the other - an overlap unique to Italian consumers' experiences--we further introduce, for the first time in a study of consumption experiences, the concept of territorialisation (De Martino 2008).

\section{Methodology}

In terms of a theory of social practices, we not only include norms and consumption environment to promote behaviours (Moraes et al. 2017), but also unconscious actions (Bourdieu 1977) and cultural values that locate habits in a particular cultural environment. While Bourdieu (1997) emphasizes the importance of embodied habits for human actions, we follow Akrivou and Di San Giorgio (2014) in considering human habits not only as reproductive actions of an existing status quo, but also as a dialogical conception, which allows for new gradual cocreations and co-evolutions of novel actions emerging between acting agents (e.g., jeweller and clients). This dialogical perspective is particularly applicable to ET (Duranti 2011) and the 
concept of territorialisation (De Martino 2008) in our luxury consumption analysis. Duranti (2011)'s methodology, which represents the theoretical concerns driving our research approach, gives pragmatic force to language, with insights taken from post-structuralist social theorists such as Anthony Giddens (1979; 1984), Pierre Bourdieu (1977; 1990; 2000) and Charles Tylor (Tylor 1985) as well as phenomenologists like Edmund Husserl and Emmanuel Levinas (Duranti 2009a). Duranti, referring to Bourdieu's concept of "habitus", also specifies that in the analysis of the communicative performance between subjects, not only the said words must be considered, but also the unconscious behavioural aspects (of which people are often unaware) must be observed and interpreted, which are in any case effective in transmitting the agentive entities related to communication and understanding of the aesthetic, moral, and practical contents transmitted through language.

Thus, Duranti perceives the world as a context full of meanings (Duranti 2011) in which subjects interpret their surroundings according to hermeneutic practices shaped through countless previous normative values. Specifically, he asserts that in most cases people do not have conscious control over their interpretations of the world, even if their interpretations, as well as values and behaviours, are limited.

In the present study, Duranti's ET is adapted to encode cultural values, as unconscious and conscious thoughts emerged during our interviews with the jeweller and his clients. By adapting ET, we can compare our participants' comments to highlight their discrete intentions to create common interpretations of ethical jewellery, Fair mined certified ethical gold (FCEG), and Canadian ethical diamonds (CED), and their perceptions of unethical versus ethical mining activities. 
In the present research, we cannot ignore the important aspect of intersubjectivity, which we use to understand both the relationship between subjects in the retail store, in which the people interviewed evolve to experience direct sensory access to each other, indirect access with imagined subjectivity (such as miners employed in the mines in other parts of the world and local communities near the mines) and a connection, acquired through personal experiences and media exposure, between consumers and an imagined environment related to mining activities.

Inevitably, perceptions of what comprises ethical jewellery given by our participants embed global advertisement narratives that frame CED and FCEG, whose influence we must consider. Nevertheless, we do not interpret transnational knowledge linked to minerals as a way to impede people's ability to be reflective in the context of commodities regimes. Quite the opposite-- considering the wide advertisement discourse, we must both highlight and contrast the cultural flexibility of interpretation that allows our participants to reshape the global messages of CEDs and FCEG as applied to Italian fine jewellery. This process of malleability is concretized through the comparisons of participants between their cultural comprehension of the idea of Made in Italy products (which are perceived as a familiar concept) and ethical jewellery.

\section{Ethnographic research}

Our research aims to provide a deeper understanding of how Francesco Belloni engages ethical clients who are exhorted to contribute, thanks to their virtuous purchases, to save the planet and defend particular categories of people (such as workers and children) employed in mining activities in other parts of the world. Our work is informed by the salient elements of an ethnographic account (Joy and Sherry 2003, 2009) via in-depth interviews with the jeweller and fifteen ethical clients, both male and female from diverse parts of Italy, and systematic data 
collection, gathered through the integration of oral and written documentation on mining activities, as well as on Fairtrade certification schemes, supply chain management linked to ethical diamonds and gold, and various case histories of ethical purchases in fine jewellery contexts (Le Billon 2008; Ghilani 2012; Moraes et al. 2017). A number of important documents were collected at The Prince of Wales Northern Heritage Centre archive in Yellowknife in Canada's Northwest Territories in order to deeply examine the economic and historical process of ethical certification and global narrative discourses linked to Canadian diamonds. We used a phenomenological approach (van Maanen 2001) combined with ET in our interviewing process with a questionnaire at the end of the ethnographic research, which allowed us to summarize the most important emergent topics. All interviews lasted from sixty to ninety minutes, were recorded with the permission of interviewees, and focused on individual experiences. Participants were chosen on the basis of their consumption and frequency of visiting Gioielleria Belloni_and their knowledge of CEDs and FCEG. Participant ages ranged from twenty-seven through forty; most were affluent.

Thanks to the methodology adopted during the interviews, subjectivity was a key component in eliciting the deeply embedded meanings of ethical purchases both in consumer experiences and in the linguistic ways deployed to explain them, to draw out participants' otherwise untapped responses. Among all interviews, commonly asked questions included: What does the concept of ethics linked to diamonds and gold mean to you? When and why did you choose to buy ethical jewellery instead of other kinds of jewellery? What does being an "ethical consumer" mean to you? How do you imagine mining activities in the Northwest Territory of Canada where ethical diamonds come from? How do you imagine mining activities in artisanal and small mines linked to Fair mined certification? And lastly, how do you perceive mining 
activity? All interviews were transcribed and analysed to identify emergent narratives and cultural values.

Table 1: Participants divided into age classes (from 25 to 40 years old; and from 40 to 60 years old)

\begin{tabular}{|c|c|}
\hline Participants from 25 to 40 years old & Participants from 40 to 60 years old \\
\hline $\begin{array}{l}\text { Marco (37, Office worker, Genoa); Filippo } \\
\text { (33, Banker, Varese); Sara (37, Doctor, } \\
\text { Brescia); Francesca (34, Art Director, Rome); } \\
\text { Giacomo (32, Geologist, Padua); Laura (37, } \\
\text { Office worker, Pistoia); Giada (37, Office } \\
\text { worker, Lecce); Pietro (37, Engineer, Milan); }\end{array}$ & $\begin{array}{l}\text { Francesco (59, Jeweler, Milan); Francesca } \\
\text { (42, Office worker, Milan); Manuela (42, } \\
\text { Manager, Torre del Greco); Mauro (51, } \\
\text { Doctor, Milan); Carlo (42, Office worker, } \\
\text { Piacenza); Letizia (40, Office worker, } \\
\text { Bollate-Milan); Umberto (50, Architect, } \\
\text { Milan); Luigi (45, Doctor, Rome); }\end{array}$ \\
\hline
\end{tabular}

During our ethnographic research, we synthesized existing narratives about CEDs and FCEG (from literature as well as mining companies' and luxury brands' reports and websites) in nodes emerging from the findings. In accordance with Sippl (2015), we found that commodity regimes targeting minerals include a range of transnational initiatives varying according to different categories such as minerals (gold, diamonds, tin, tungsten); issues of interest (conflict, environment, poverty, worker rights); producer scale (large versus small or artisanal scale); program type (third-party certification, building projects, second-party labelling); and program duration (one-off grant-funded pilots versus ongoing, self-sustaining initiatives) (Sippl 2015; Van Bockstael 2014). To better understand how the global narratives on CEDs and FCEG interacted with Italian ethical consumers' discourses, we focused on "minerals" (gold and diamonds); "issue of interest" (conflict, worker rights, environment); "producer scale targeted" (large scale in Canadian context; small or artisanal scale in South countries mines); "program type" (traceability, referring to the physical tracking of minerals at all points on the supply chain, 
from the mine of origin to the customer, and certifications), and "imagined geographic dimension" as explicated in the media (Africa versus Canada; polluting small and artisanal mines in undefined places in the world versus sustainable small and artisanal mines thanks to the Fair mined program).

A key difference between "minerals" and "issues of interests" is their respective differing global narratives: diamonds versus conflicts and human rights, and gold versus environmental pollution and labelling programs. "Blood diamonds" are portrayed as funding violence and wars (Le Billon 2006; D'Angelo 2019), and are linked to criminal projects, motivated by lust for resources and viewed as an easily accessed loot source (Collier, Hoeffler 1998; Keen 1998), with warlords (De Boeck 2001) viewed as exploiters of men, women, and children subjected to widespread abuses (Le Billon 2008).

The first guarantee encourages consumers to have an ethical perception of diamonds, and is linked to our category of "producer scale targeted" which, in the case of Canadian diamonds, is associated with large-scale operations. As some participants noted, industrial exploitation is associated with stronger economic growth: a poor human-rights record directly equals lower prices. Specifically, the exploitation of primary or kimberlite requires industrialization [kimberlite is an igneous rock, which may feature diamonds]. In contrast, secondary or alluvial deposits, often found in poorer countries, are open to artisanal mining with or without the official consent of authorities (Le Billon 2008). Privileging industrial over artisanal mining has significant political consequences. Compared to artisanal exploitation, industrialization concentrates power in the hands of the state that, in the case of Canada, globally certifies rhetoric on ethical employment opportunities and reflects the preferences of foreign extractive companies obligated to respect Canadian laws. Thus, diamonds can be perceived as emblemizing Canada 
itself (Banet-Weiser 2012) in which social issues are the platform not only to sell products but also to sell the Canadian Government brand. ${ }^{\mathrm{i}}$ In this context, CEDs are also related to the category of "program type" through certification of origin. Indeed, the government of the Northwest Territories of Canada is the first in the world to issue government-certified certificates of authenticity to diamonds that are mined, cut, and polished in the Northwest Territories. ${ }^{\text {ii }}$ The Canadian brand is globally presented as signifying the purity of the diamonds, both geologically and politically. This discourse proposes a Canadian diamond mine's characterization as, in environmental terms, incorporating “clean mining” and, primarily, embodying social responsibility. However, the actual process of Canadian diamond certification is somewhat nebulous, in that not all diamonds from Canada carry certification that is from Canada. In order to state that such diamonds are Canadian in origin, their certification should be traceable all the way from the rough diamond to the wholesaler's office and finally through to the retailer who sells the diamond. In order to certifiably be from Canada, the diamond has to have a logo for the Canadian Diamond Code of Conduct and the seller must be listed as a member of the Canadian Diamond Code of Conduct. (https://purediamond.ca/info/how-to-make-sure-your-diamond-is$\underline{\text { canadian/). }}$

In its response to the "blood diamonds" discourse surrounding African diamonds, Canada has been the leading country in proposing a certification scheme, launched in 2003, that surpassed the Kimberley Process (KP) plan, a certification scheme itself, initiated in 2002, to prevent blood diamonds from entering the market for rough diamonds (Bernstein 1992). The KP can fairly be represented as the project preceding the Canadian diamond certification in the fight against conflict diamonds. For decades, the illegal process of mining and marketing rough diamonds was accepted by mining companies. In 2000, however, De Beers announced that they 
were no longer willing to trade diamonds from conflict zones, particularly from African mining contexts. Governments and mining industries began to work together to combat the illegal diamond trade and, by founding the World Diamond Council, they signed the KP plan. In contrast to Canada's ethical diamond certification of origin, the KP does not allow consumers to know the exact origin of a given diamond, but simply guarantees, thanks to the signature of governments, mining companies, and other for-profit and non-profit organizations, as well as of private citizens, that a specific diamond entering the market has not been derived from illegal trafficking managed by criminal organizations (Haufler 2009).

Thanks to a global marketing strategy of the mining companies operating in Canada, the opposition is automatically created between state-regulated Canadian mines and African artisanal mines: two opposite peaks in the geopolitical landscape of diamond mining and trade (Le Billon 2008). Schlosser (2013) argues that CEDs, presented as the pure alternative to African "blood diamonds" often constitute a crude attempt to establish linear links between different places that invoke poverty and natural resources (D'Angelo 2019) as well as images of Africa as synonymous with violence and primitivism (Le Billon 2006) —in direct opposition to symbolic imagery of northern Canada as a pristine and implicitly moral rural space white with snow.

The global narrative regarding artisanal and small-scale mining centers on health hazards, particularly because mercury amalgamation in gold mining can precipitate human and environmental damage. As numerous studies show, in addition to air and water pollution due to cyanide and mercury (used for the sorting of ore from waste rock), the environmental degradation caused by the mine also compromises the livelihoods of those living near mining areas (de Theije and Salman 2018). Moreover, environmental pollution raises issues of land 
ownership conflicts involving miners, collective or private concession holders, and indigenous communities (de Theije and Salman 2018).

Discourses on artisanal and small-scale mines create images implying that gold mining directly leads to or indirectly financed armed conflicts over the mineral. This representation is supported by many studies on African artisanal mines (Lujala et al. 2005; de Theije and Salman, 2018) in which mined diamonds finance rebel groups (d'Angelo 2019; Verbrugge 2017). As of this writing distinctions between "artisanal and small-scale mining" are undefined, and often conflated in the literature. Many scholars (De Boeck 2001; Lujala et al. 2005; Kyba et al. 2019) affirm that artisanal and small-scale mining (ASM) in combination are largely an informal sector with limited available information on production, revenues, operations, and even the location of activities. Empirical evidence supporting formalization of this sector as a means to improve working conditions (e.g., by the Minamata Convention, a global treaty designed to protect human health and the environment from the adverse effects of mercury use in mining activities) is largely unavailable to researchers. We do know that artisanal mining activity is typically informal, lacks sophisticated machinery, and attracts destitute workers. In contrast, small-scale mining activity is more organized, although miners do not necessarily use sophisticated machinery even if they have higher revenue turnover and legal licenses.

Over the past thirty years, both small-scale and artisanal mines have increased globally (de Theije and Salman 2018), yet as of this writing, no existing agreement fully defines and regulates either type of mines, a situation complicated by the fact that what regulation there is varies from state to state, according to the internal politics and economy of each nation.

In our category of "producer scale targeted" linked to artisanal and small-scale mines, the general representation of artisanal mines depicts scenarios in which small groups of unorganized 
workers, often within families, are involved in mining, while the representation of small-scale mines supports narratives of mining management through small cooperatives. Drawing on existing literature, however, both types of mining organizations can be regulated legally or illegally (Hentschel et al. 2003; Jennings 1999).

In the 1990s, governments in Columbia, Peru, and South Africa began promoting an image of environmental sustainability. Given its role in tackling the degradation caused by mining activities and providing supply-chain tracking guaranteeing Fair labour and environmental policies, such sustainability represents an alternative to environmentally damaging mining activities. The Fair mined program aims to formalize artisanal and small-scale mines into a profitable activity using efficient technologies, end child and labour exploitation, and reduce poverty in participating countries. Beginning in 2009, artisanal and small-scale mines worked with the Fairtrade and Fair mined Gold (Childs 2008; Valerio 2013). Starting in 2013, the world standard for defining mined gold, silver, and platinum evolved from Standard Zero (the world's pioneering standard for mined gold, silver, and platinum) to Standard 2.0 (created in 2014 and involving stakeholders throughout the supply chain). A third-party certification program checks compliance with the standard for artisanal and small-scale mines every year. Today twelve artisanal and small-scale mines worldwide are certified as Fair mined (two in Peru, two in Bolivia, seven in Colombia, and one in Mongolia). Certified artisanal and small-scale mines receive at least ninety-five percent of the gold price set by the London Bullion Market Association, which is higher than the usual market price (European Commission 2010). In addition, miners receive a Fair mined premium of USD \$4,000 per kilogram (Kempf 2017). Taken as a whole, the imagined geography of symbolic environmentally friendly mines, and of miners working in safe conditions with Fair wages, is further entrenched in consumers' minds. 
3.1 Gioielleria Belloni: contextualisation of ethnographic research on Italian fine jewellery purchases

Gioielleria Belloni has a venerable history dating to 1926, when the grandfather of the current owner, Francesco Belloni, opened the store in Milan. With Francesco at the helm, Gioielleria Belloni first engaged in charitable activities in 2002, donating part of the proceeds from their jewellery sales on Valentine's Day and Christmas to non-profits active against cancer and supporting minors in poverty; moreover, ten percent of the customer jewellery purchases were donated to various charitable organizations. These donations were always communicated locally, through regional television networks or in radio broadcasts, often in advance.

In 2003, Francesco attempted to donate to the Londoner Survival International (a human rights organization formed in 1969 whose campaigns support human rights in developing countries); the organization refused the donation based on Belloni's connection to diamond sales. The group had already been boycotting the Diamond Trading Company and De Beers in Botswana for several years (https://www.survivalinternational.org/); the latter company had expropriated the Bushmen [hunter-gatherers indigenous to Southern Africa] from their land, especially in the Kalahari Desert, where diamond deposits had been found.

At the time, Franceso was sourcing African diamonds only. Survival International, in response to his plea, provided an alternative: diamonds from the Ekati and Diavik mines in the Northwest Territories of Canada. ${ }^{\text {iii }}$ In 2005, Gioielleria Belloni began selling CEDs in Italy; the company's website terms Fair mined gold "The gold to be proud of". A grateful clientele immediately perceived Canadian gemstones as free from illicit trafficking, unlike African diamonds. Francesco specifically noted that the Canadian origin of his diamonds was a key selling point to his customers, to the point that he identifies his clientele as ethical customers, as 
opposed to other customers who choose not to purchase ethically produced jewellery. Francesco created the Ethical Diamonds brand, whose logo is a stylized diamond featuring a red maple leaf, which he has promoted widely online and through advertisements on Radio Popolare di Milano, a station with a politically liberal viewpoint whose listeners tend to embrace environmental sustainability and ethical labour practices.

The Ethical Diamonds brand focuses on supply chain certification. As Francisco noted during our interview with him, the Gioielleria Belloni website quickly became a major ecommerce source, both locally and worldwide for ethical Canadian diamonds. ${ }^{\text {iv} B e f o r e ~}$ introducing CEDs, the jewellery shop sold around 60 diamonds a year; in recent years, that number has hovered around 300, specifically of CEDs. In 2008, Gioielleria Belloni also started selling FCEG from artisan mines in Columbia and Peru, thus creating the "Ethical Gold" brand. Francesco buys pure gold in grains and sends it to workshops outside the shop that process it, ensuring that certified Fair mined gold is separated from its non-certified counterpart.

\section{Encoding values: How Italian ethical consumers perform jewellery purchases}

Applying ET allows us to study agency through two different lenses: performance and encoding (Duranti 2001; 2004). Close attention to the performance of language suggests that even before constituting specific speech acts, the use of language affirms the speaker as well as the listener as potential agents. Thus, we apply the performance of language to our analysis of interviews to highlight how Francesco and his clients co-create a discursive universe on CEDs and FCEG, as well as on ethical mining activities and ethical consumption. In adapting Duranti's encoding theory in our analysis of interviews, we substituted an ethnographical codification of values and representations of Duranti's original linguistic application on the study of grammar. 
Duranti's explication about the ergative-absolutive type of language (EATL) inspired us to construct a frame able to encode ethical purchasers' values. ${ }^{\mathrm{v}}$ Notably, the key assumption we derived from EATL is the dependency of the agent's identity (i.e., jeweller and clients), as well as their values and behaviours, on the object (i.e., ethical jewellery).

Premising that CEDs and FCEG (as objects driving agency in Italian fine jewellery consumption) establish the background of our analysis, we summarize in Table 2 below data derived from our interviews: 1) the main values that encourage ethical clients to choose ethical jewellery; 2) the ideological representation of mining activity; and 3) the cultural representation of ethical mining activities.

Table 2: Data Derived from our Interviews with Participants

\begin{tabular}{|l|l|l|}
\hline $\begin{array}{l}\text { Main values able to guide } \\
\text { clients toward ethical } \\
\text { choices }\end{array}$ & $\begin{array}{l}\text { Ideological representation } \\
\text { of mining activity }\end{array}$ & $\begin{array}{l}\text { Ideological representation } \\
\text { of ethical mining activity }\end{array}$ \\
\hline $\begin{array}{l}\text { Human rights: } 15 \text { clients } \\
\text { interviewed }\end{array}$ & $\begin{array}{l}\text { Hard work: } 12 \text { clients } \\
\text { interviewed }\end{array}$ & $\begin{array}{l}\text { Workers respected: } 8 \text { clients } \\
\text { interviewed }\end{array}$ \\
\hline Environmental impacts: 11 & $\begin{array}{l}\text { Risky work: } 7 \text { clients } \\
\text { interviewed }\end{array}$ & $\begin{array}{l}\text { Safe workplace: } 5 \text { clients } \\
\text { interviewed }\end{array}$ \\
\hline Guilt sense: 9 clients & Underpaid work: 4 clients & Fair wages: 4 clients \\
interviewed & interviewed & interviewed \\
\hline
\end{tabular}


As illustrated in Table 2, Gioielleria Belloni clients have a clear perception of both the values that guide them in their ethical jewellery purchases, and of what comprises an ethical mine. Starting from a quantitative point of view, Figure 2 shows that the number of participants in the two first columns is higher than the third column--many people interviewed gave two or three explications in the same response-while as shown in the third column, just two clients gave two interpretations of ethical mines within a single reply; the remainder each gave only one interpretation. From a qualitative perspective, this information suggests that participants had not fully embodied the concept of ethical mining, nor, as hypothesized below, (as shown below in Section 5), of ethical jewellery.

This evaluation allows us to clarify how Gioielleria Belloni’s ethical customers distinguish themselves through their purchase choices from store clients. Based on our data, we surmise that, while they were not fully aware of what constituted ethical mining activity, their purchases of CEDs and FCEG fine jewellery allowed for self-expression as moral individuals through consumption. Furthermore, we can hypothesize that ethical fine jewellery embodies a moral code and, as such, serves as a means for clients to experience not only their personal attitudes toward consumption but also their existence as a whole. Thus, as a result of their ethical choices, they have achieved their own integration within the larger world.

We asked Francesco the same set of questions offered to our other participants, as summarized below in Table 3 .

Table 3: Data Derived from Retailer

\begin{tabular}{|l|l|l|}
\hline Main values in the & $\begin{array}{l}\text { Ideological representation } \\
\text { jeweller's suggestions to his }\end{array}$ & $\begin{array}{l}\text { Ideological representation } \\
\text { of ethical mining activity }\end{array}$ \\
\hline
\end{tabular}




\begin{tabular}{|c|c|c|}
\hline $\begin{array}{l}\text { clients in the realm of } \\
\text { ethical purchases }\end{array}$ & & \\
\hline $\begin{array}{l}\text { Protect workers' rights } \\
\text { linked to diamonds and gold } \\
\text { extraction. }\end{array}$ & $\begin{array}{l}\text { Workers don't follow safety } \\
\text { protocols in poor countries. }\end{array}$ & $\begin{array}{l}\text { Mining companies operating } \\
\text { in Canada follow Canadian } \\
\text { laws; therefore, workers' } \\
\text { rights are respected. } \\
\text { Thanks to Fair mined } \\
\text { certification we have the } \\
\text { same guarantee for artisanal } \\
\text { and small-scale mines. }\end{array}$ \\
\hline $\begin{array}{l}\text { Environmental safeguards } \\
\text { above all for large-scale } \\
\text { industrialisation, even if } \\
\text { artisanal and small-scale } \\
\text { mines have less effect on the } \\
\text { environment. }\end{array}$ & $\begin{array}{l}\text { Uncontrolled use of mercury } \\
\text { in small-scale and artisanal } \\
\text { mines. }\end{array}$ & $\begin{array}{l}\text { More sustainability thanks to } \\
\text { recurring controls. }\end{array}$ \\
\hline
\end{tabular}

In comparing the communication styles and responses of Francesco and his clients, the concept of intersubjectivity - between the former and the latter, as well as between our participants and their varied theorized communities of miners and geographical spaces--would appear to play a crucial role. Intersubjectivity is the common denominator in all responses creating high involvement among participants, such that they become a community comprising 
people who share common values, experiences, and ideas, whose setting is a retail store (or its online presence). Furthermore, our participants' answers displayed a strong communicative empathy. Some clients connected characteristics related to ethical jewellery with their conception of Made in Italy products, as shown below in Section 5.

\subsection{Performance in the discursive universe on ethical jewellery}

To capture our understanding of the Italian ethical luxury performance as experienced by its practitioners, we turn to the discursive universe on CEDs and FCEG as extrapolated from our interviews, to highlight the cultural values that inform Francesco's interactions with customers as he guides them toward ethical purchases. Specifically, following Duranti's assertion in which agency is enacted and represented through language, we have aggregated conceptual nucleuses, derived from our interviews, that articulated specific values, thoughts, and behaviours. During our conversations with Francesco and several customers, variations on the phrase «We want to be different thanks to ethical options» often emerged. Our participant Luigi, a repeat ethical client, took pride in his potential to influence the wider market: «If you are no longer buying [non-ethical] products, its manufacturer loses business and will perhaps change its ways. As a consumer, every time you buy something you can make a difference».

With Figure 1 below, we show how «to be different» is converted to perceptions of ethical behavior, for both Francesco and his customers.

Figure 1: Conversion of the concept «to be different» into ethical behaviours

Canadian ethical diamonds and Fair mined certified ethical gold are chosen instead of other kinds of Jewellry thanks to their certification of origin 

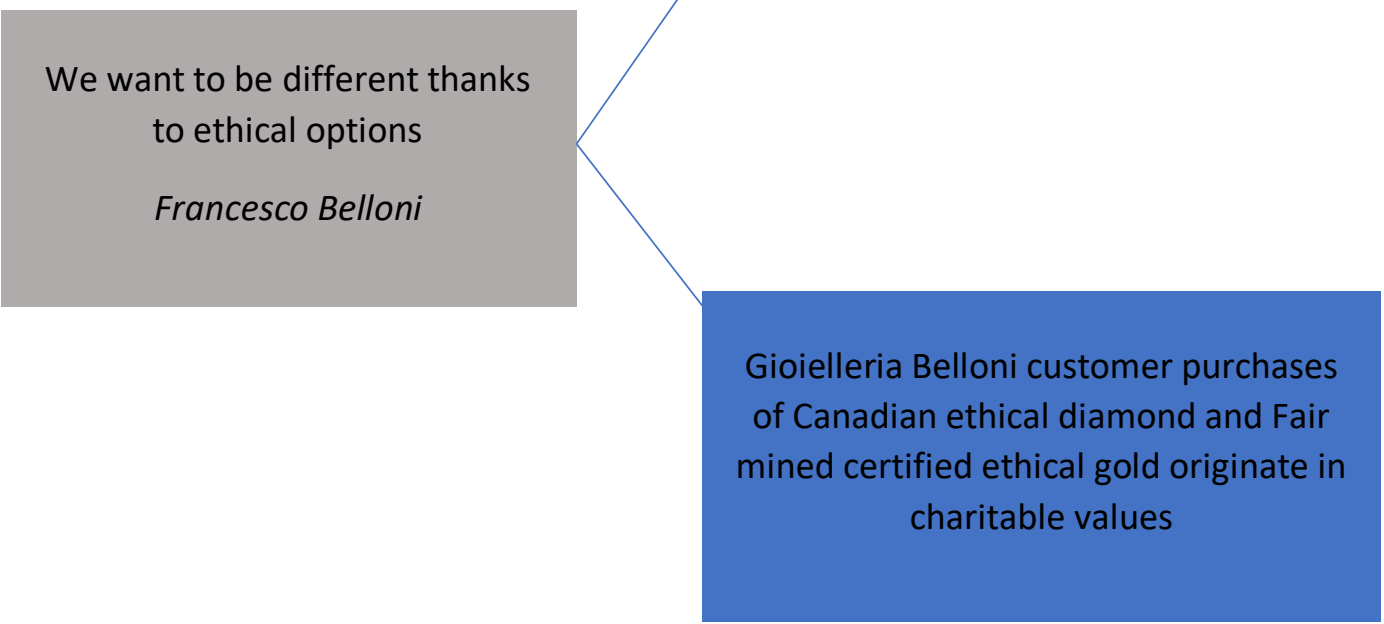

Starting from Figure 1, we build four categories in which we summarize our interview data, all precipitated by the phrase «We want to be different thanks to ethical options». These categories are arranged along two axes that comprise the two concepts of "guarantee" and "charity", around which the discursive universes on ethical jewellery of our participants were built while distinguishing Francesco's discourses from those of his clients. The concept connecting every category is "supply chain".

Figure 2: Discursive universes on ethical jewellery of interviews participant 


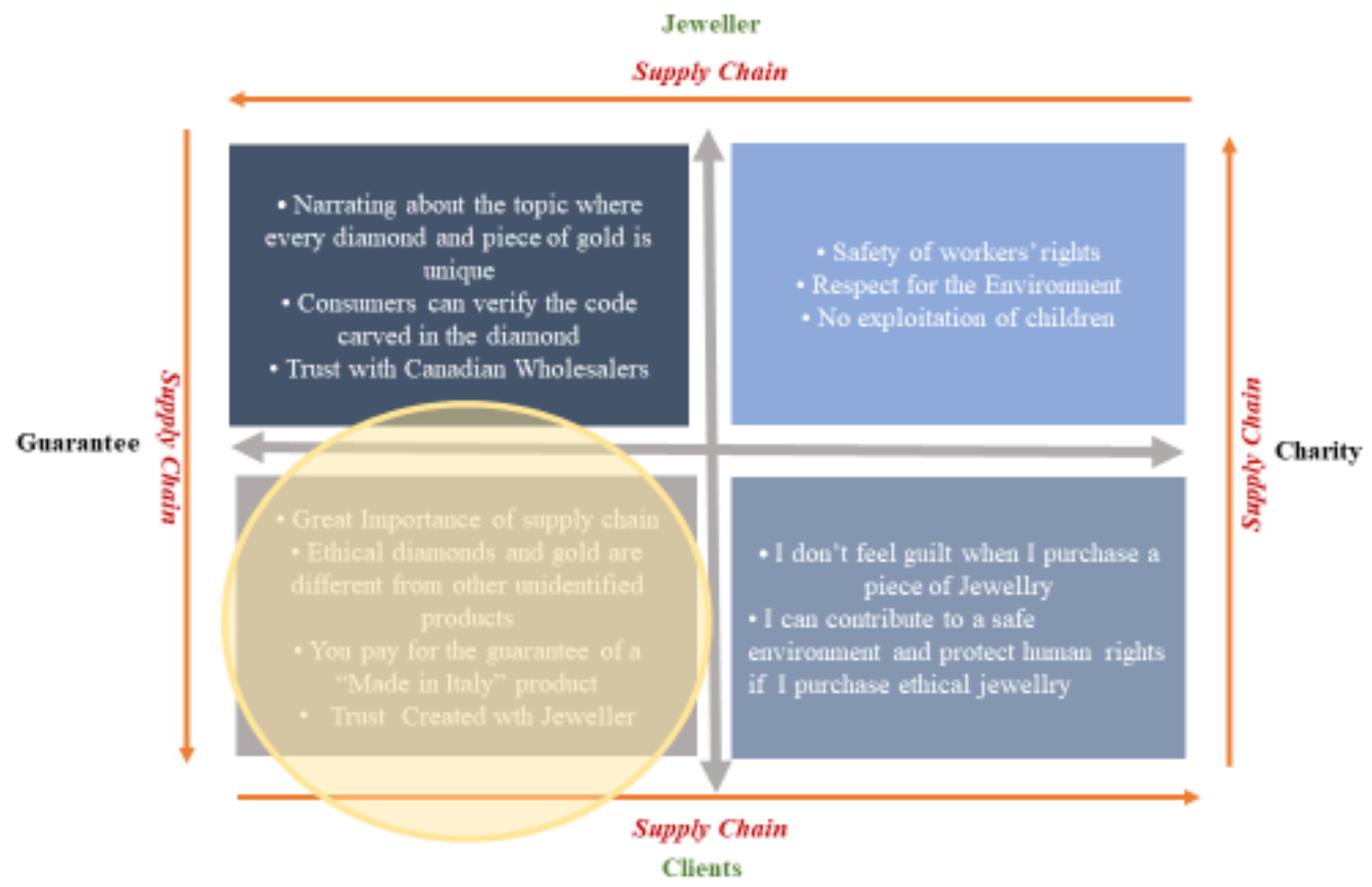

Jeweller's discourse around warranty value

Consumers' perceptions about warranty value
Jeweller's discourse around charity value

Consumers' perceptions about charity value

Compared to other case histories from extant literature (Moraes et al. 2017; Cervellon and Wernefelt 2012), Figure 2 allows us to convey both the similarities and the discrete interpretations (as highlighted in the lower-left category) of ethical jewellery given by our participants. Focusing on clients' responses, our study aligns with other analyses of fine jewellery ethics (i.e., Moraes et al. 2017; Carrington et al. 2014) on the prioritisation of ethical issues when consumers purchase jewellery. These issues encourage consumers to be adamant about buying only conflict-free jewellery. Furthermore, most participants mentioned the issue of 
"blood diamonds" as seen in various media (e.g., the 2006 film Blood Diamond starring Leonardo DiCaprio) and in investigative reporting on labour and human rights issues, consistent with participants' knowledge about supply chains being important in ethical purchases (Moraes et al. 2017). Specifically, our study also underscores the relationship between ethical issues, supply chains, and the possibility of jewellery consumption free of guilt (an idea that clearly motivated our participants and appeared to have emerged in response to Francesco's discourse of charity). Many of our clientele participants reported being concerned by the potential for negative social and environmental impacts from their purchase habits (Ki et al. 2017). Consumers may experience guilt when their luxury consumption, which often denotes nonessential and extravagant spending - the embodiment of conspicuous consumption--contradicts their values. Our participant Umberto explained his choice of ethical jewellery:

«I can buy ethical jewellery. [The pieces] ... cost more than other jewellery, but they... [reflect].. my point of view. I don't want to buy a diamond or gold that can damage other parts of the world. I'm lucky, and I try to share my luck around me as I can».

Letizia, another participant, told us how she tries to reduce her sense of remorse by purchasing ethical jewellery:

«I think that Fair mined gives guarantees... to the workers, to local communities, and to the consumers about environmental and ethical questions. If I buy a ring or another piece of jewellery, I know that my purchase doesn't damage the environment or other people. I don't feel guilty because I want jewellery. I think that projects [such] as Fair mined can help people to live better». 
As demonstrated above, clients can convert the value of "having" to a value of "being". As a result, they may experience reduced feelings of guilt that otherwise might have been triggered by luxury consumption. In this context, a charitable narrative told by Francesco can be an effective guilt-reducing strategy and can encourage brand loyalty. Extant research (Strahilevitz, Myers 1998; Varadarajan, Menon 1988) explains the impact (as shown in the above-right category in Figure 5), of a business implementing a perception of a cause-related campaign to support human rights or environmental causes: enhanced positive brand awareness (Berger et al. 1999, Brønn, Vrioni 2001, Gupta, Pirsch 2006a) and a short and long-term boost in sales (Strahilevitz 1999, Strahilevitz, Myers 1998, Varadarajan, Menon 1988).

For our participants, the concept of a "guarantee" introduced a narrative around the supply chain. Both Francesco and his clients immediately connected the concept of the supply chain to the concept of "guarantee" and perceived it as indicative of the uniqueness linked to each piece of ethical jewellery. As Francesco reported to us, the characteristic of uniqueness is perceived as belonging only to the Canadian diamonds and to FCEG:

«Canadian diamonds are free from illicit traffic. ...only Canadian diamonds can guarantee this through [the] certification of origin. For example, the Kimberley Process doesn't tell me where a diamond comes from. It is like when you go to the supermarket and you want to know where the food comes from. It is absurd that this process isn't applied to the diamond as well. Especially, for Canadian diamonds, the supply chain works well (...). Diamonds from Canada have a maple leaf carved by the laser and codes with numbers and letters. In this way, you can understand that every diamond is unique. Moreover, every wholesaler has to have a filing system. Therefore, every consumer can insert the diamond's code on a website and know 
who the supplier is, the characteristic of the stone, and its size before being carved. The consumers appreciate this characteristic. For Fair mined gold is different. I have my gold from European suppliers who buy the metal from Fair mined-certified South American mines. They sell to me pure gold in grains, and then I send it to workshops outside my shop that process it, ensuring that special care is taken to separate it from non-certified gold».

The concept of "guarantee" has strong connections to perceptions of "relationship" and "trust" with two different applications. The first refers to the relationship and trust created over time between Francesco with his Canadian diamonds' wholesalers in Canada and Fair mined gold suppliers in Switzerland, Germany, and France. As Francesco reported to us: «I have a good relationship with my suppliers. I can tell them: “Can I pay you next month?”, and they reply to me: "Ok". I could create this familiarity with them during the last years. (...) They trust me, as I trust them»). A sense of familiarity, and thus trust, was also experienced by Francesco's ethical clients towards the jeweller (as Luigi affirmed: «Francesco Belloni is (...) a point of reference for me»). The relationship between the jeweller and his customers is initially characterised through education, as Francesco defines the rationale for ethical jewellery, as Francesco asserted: «My clients are usually prepared, they read the news, etc. The consumers that want ethical jewellery have to be very motivated to search for this kind of product. There are other consumers who come to the store and I explain the ethical alternative. I always explain to the consumers... about the supply chain, and this is the most important thing for them». 
5. Territorialisation, ethical jewellery, and the Made in Italy concept: How Italian ethical consumers interpret Canadian ethical diamonds and Fair mined certified gold

Figure 2 in the lower-left category shows the specific interpretations of ethical jewellery given by our clientele participants. To discuss this cultural meaning, we reclaim the concept of uniqueness, which is directly linked to the concept of differentiation between CEDs, FCEG, and jewellery produced without ethical production and manufacturing processes. The presence of a certification of origin instantly reassures consumers that a given piece of jewellery has been ethically created. Moreover, such certification engenders a higher price point, which consumers willingly pay to know the path followed by diamonds and gold from mines to purchase. Interestingly, our clientele participants were willing to pay more not only for an ethical piece of jewellery, but also for a Made in Italy product. As our participant Umberto noted:

«Many people in Italy are accustomed to evaluating the quality of the products. My family and I are also very attentive to the "Made in Italy" [brand], and we always try to buy Italian products, even if often they cost more than other goods. I think that ethical diamonds and gold could be compared with Made in Italy products, where you can... know where the raw materials come from, as well as for the characteristic of costs».

We can thus hypothesize that the parallelism between ethical jewellery and Made in Italy products could be an intrinsically Italian approach to conceptualizing CED and FCEG through a well-known cultural and economic concept. As emerged during other interviews, such parallelism between the categories of products also relates to consumer cultural perceptions of highly educated workers, with significant accumulation of experience. Umberto told us: 
«When I think about ethical mines, I think that the workplace is safe for workers and it is a warranty for the consumers. (In the ethical mines) companies allow the worker to be safe and well paid... I think that miners (in Canada) are professional workers, chosen by the company for their skills. The company analyses their $\mathrm{CVs}$, and maybe it can also test... [the workers] to... [gauge] their expertise. Then they can work in the mine... I also think that these workers can earn a good salary, better than other jobs, thanks to the Fair mined label».

While the parallelism between CEDs, FCEG, and the cultural idea of Made in Italy products has never previously been studied, the concept of territorialisation (De Martino 2008) can help us understand this parallelism. Territorialisation (appaesamento is the original definition coined by Ernesto De Martino) denotes the opposition of spaesamento (which derives from the Italian word spaesato) that translates to "bewildered"; thus, territorialisation is the exact opposite of bewildered. In our analysis, the concept of territorialisation is useful in studying the stratified way in which new and old meanings are blended by our Italian clientele interviewees. De Martino's phrase the «non-problematic setting of the obvious» (De Martino 1977: 95), explains how the familiarity of acts and objects that constitute our world, as well as our knowledge expressed through linguistic and non-linguistic means, allow us to gradually expand our known territory, embracing new meanings and practices. In this way, territorialisation is a form of the «domestication of the world» (De Martino 1977: 96), in which an individual's understanding of new acquisitions (whether of the mind (e.g., cultural or linguistic,) or the physical world (e.g., the import of new products), is filtered through the tradition in which a person belongs. In this way, through the concept of territorialisation (ibid.), the individual pragmatically acquires cognitive security and an emotional trust that allows for being in the world (Sasso 2001). De 
Martino's conceptual approach to territorialisation, from the German philosopher Martin Heidegger, implies the idea of building and living, not only of places but also of forms of knowledge that in turn are the practical condition underlying the cultural creation of subjectivity (Berardini 2015). To further explain De Martino's theorization of territorialisation, it is useful to briefly retrace the theoretical path through which the Italian anthropologist formulated his concept. Starting from Heidegger's idea of die Wohnenden ("the inhabitants"), De Martino builds the concept of territorialisation, while also taking up the concept of bauen ("to build") theorized by the German philosopher, which derives from the ancient high-German buan ("to stay", "to remain") and which constitutes, going back to the genesis of Saxon languages, the concept bhu-beo, which is the same as ich bin ("I am”). De Martino also derived from Heidegger the other meaning of bauen linked to the idea of "constructing", understood in turn as "looking after". In this way, building not only identifies the concept of "construct", but also means, above all, to remain preserved from threats thanks to the progressive expansion of knowledge that domesticates the unknown by making it known (Berardini, Marrafa 2016).

The analogy between CEDs, FCEG, and the cultural idea of Made in Italy product allows us to hypothesize, as shown in paragraph four of Figure 2., our participants' lack of a full understanding of the first two categories of products. Their parallelism could be explained through the probability that they have not yet fully understood ethical jewellery to the same degree to which they currently understand the concept of Made in Italy products, due to a deep economic and historical embodiment. In this case, the analogy provides a frame wherein new insights and inferences are blended with known experiences. Through this process, the concept of ethical jewellery can gradually be made familiar and therefore begin to be easily understandable and incorporated into lived experience. In accord with Sanga, in this way, a 
cultural act becomes "natural" (Sanga 1997, 2001). The mechanism of blending unfolds via the cultural appropriation of new concepts (e.g., Canadian diamonds) becoming understandable and eventually familiar through consumer perceptions of a new concept as similar to, or even an extension of, existing concepts (e.g., the Made in Italy brand). Thus, as we demonstrate through

this study, consumers can perceive messages regarding new brands only within the boundaries of language and local culture. Once a new concept has effectively been assimilated into the familiar, both culturally and linguistically, the concept itself automatically becomes understandable; a workable frame has been provided that in turn drives purchase decisions and, in the context of ethical jewellery, allows customers to behave ethically. Our considerations go even farther, proposing a new category that is not only theoretical, but also practical and thus useful for marketing, which we define as "fair and ethically made in Italy". With this category, we can achieve a deeper understanding of how Italian consumers conceive, through their cultural background, the concepts of "fair" and "ethical" concerning jewellery and, in general, to luxury goods. From an applicative point of view, this new category can also be a useful tool for understanding the perspective of consumers in Italy. Ultimately, the concept of "fair and ethically made in Italy" can be a vital component in creating ad hoc proposals for the Italian market aimed primarily at the consumption of quality or niche products, such as goods classified as ethical and sustainable.

\section{References}

Akrivou K Di San Giorgio LT (2014) A dialogical conception of Habitus: allowing human freedom and restoring the social basis of learning. Frontiers in Human Neuroscience 8:14. doi: $\underline{10.3389 / \text { fnhum.2014.00432 }}$ 
Arsel Z Bean J (2013) Taste Regimes and Market-Mediated Practice. Journal of Consumer Research 39(5): 899-917. doi: $10.1086 / 666595$

Banet-Weiser S (2012) Authentic:Tthe Politics of Ambivalence in a Brand Culture. New York University Press, New York

Berger IE Cunningham PH Kozinets RV (1999). Consumer persuasion through cause-related advertising. In: Arnould E Scott L (Eds.) Advances in Consumer Research. Association for Consumer Research. University of Toronto, p 491-497

Berardini SG (2015) Presenza e negazione. Ernesto De Martino tra filosofia, storia e religione. Edizioni ETS, Pisa

Berardini SG, Marrafa M (2016) Presenza e crisi della presenza tra filosofia e psicologia. Consecutio Rerum. Rivista Critica della Postmodernità 1(1):93-112.

Bernstein L (1992) Opting out of the legal system: Extralegal contractual relations in the diamond industry. Journal of Legal Studies 21(1):115-57. doi:10.1086/467902

Bourdieu P (1977) Outline of a Theory of Practice. Cambridge umiversity Press, New York

Bourdieu P (1990) In Other Words: Essays Towards a Reflexive Sociology. Standford University Press, Redwood City, California

Bourdieu P (2000) Pascalian Meditations. Standford University Press, Redwood City, California

Brønn PS Vrioni AB (2001) Corporate social responsibility and cause-related marketing: an overview. International Journal of Advertising 20(2): 207-222. doi:

$\underline{10.1080 / 02650487.2001 .11104887}$

Carrington MJ, Neville BA, Withwell GJ (2014) "Lost in translation: Exploring the ethical consumer intention-behavior gap" Journal of Business Research 67(1):2759-2767.

doi:10.1016/j.jbusres.2012.09.022

Cervellon MC, Wernerfelt AS (2012) "Knowledge sharing among green fashion communities online: Lessons for the sustainable supply chain" Journal of Fashion Marketing \& Management 16(2): 176-192

Childs J (2008) Reforming small-scale mining in sub-Saharan Africa: political and ideological challenges to a Fair-Trade gold initiative. Resources Policy 33(4):203-209 
Collier P\& Hoeffler A (1998) On economic causes of civil war._Oxford Economic Papers 50(4): 563-573. doi: $10.1093 / \mathrm{oep} / 50.4 .563$

D'Angelo L (2019) Diamanti. Pratiche e stereotipi dell'estrazione mineraria in Sierra Leone. Meltemi, Milano

Davies NB, Krebs JR, West SA (2012) An Introduction to Behavioural Ecology.WileyBlackwell, Oxford

De Boeck F, (2001) "Garimpeiro worlds: Digging, dying and "hunting" for diamonds in Angola. Review African Political Economy 28(90):549-562. doi: 10.1080/03056240108704565

De Martino E, (1977; 2008) La fine del mondo. Einaudi. Torino

De Theije M \& Salman T (2018) Conflicts in marginal locations: Small-scale gold mining in the Amazon. In: Lahiri-Dutt K (ed) Between the Plough and the Pick. Informal, artisanal and smallscale mining the contemporary world. Australian National University Press, Acton, pp. 261-274. doi: 10.22459/BPP.03.2018

Duranti A, (2001) Performance and Encoding of Agency in Historical-Natural Languages. In: Henning K Netherton N Peterson L C (ed) Texas linguistic forum 44. University of Texas Press, Austin, p 266-287

Duranti A (2004) Agency in Language. In: Duranti A (ed) A Companion to Linguistic Anthropology, Blackwell, Malden MA, p. 451-473

Duranti A, (2011) Ethnopragmathic and Beyond: Intentionality and Agency Across Languages and Cultures. In: Baraldi C, Borsari A, Carli A, Aurora CO (ed) Hybrids, Differences, Visions. On the Study of Culture, Davies Group, Aurora, p. 151-168

Echeverri P Skålén, (2011) Co-creation and co-destruction: A practice-theory based study of interactive value formation. Marketing theory 11(3): 351-373. doi: $\underline{10.1177 / 1470593111408181}$

Evans-Lacko S, Henderson C, \& Thornicroft G (2012) Public knowledge, attitudes and behaviour regarding people with mental illness in England 2009-2012. The British Journal of Psichiatry 202(55): 51-57. doi:https://doi.org/10.1192/bjp.bp.112.112979 
Fuentes JM \& Martìnez-Jurado PJ (2014) Lean Management, Supply Chain Management and Sustainability: A Literature Review. Journal of Cleaner Production 85(15): 134-150. doi: $\underline{10.1016 / j . j c l e p r o .2013 .09 .042}$

Giddens A, (1979) Central Problems in Social Theory: Action, Structure, and Contradiction in Social Theory. Action, Structure and Contradittion in Social Analysis. University of California Press, Los Angeles

Giddens A, (1984) The Constitution of Society: Outline of the Theory of Structuration. Outline of the Theory of Structuration. University of California Press, Los Angeles

Ghilani JL (2012) DeBeers" "Fighting Diamonds": Recruiting American Consumers in World War II Advertising. Journal of Communication Inquiry 36(3):222 -245. doi: $\underline{10.1177 / 0196859912453320}$

Gupta S \& Pirsch J (2006a) The company-cause-customer fit decision in cause-related marketing. Journal of Consumer Marketing 23(6): 314-326. doi: 10.1108/07363760610701850

Harvey J, Bolam H, Gregory D , \& Erdos G (2001) The effectiveness of training to change safety culture and attitudes within a highly regulated environment. Personnel Review 30(6): 615-636. doi: $\underline{\text { 10.1108/EUM0000000005976 }}$

Haufler V, (2009) The Kimberley Process Certification Scheme: An Innovation in Global Governance and Conflict Prevention. Journal of Business Ethics, 89(1):403-416. doi:10.1007/s10551-010-0401-9

Hentschel T, Hruschka F, \& Priester M (2003) Artisanal and Small-Scale Mining - Challenges and Opportunities. IED, London

Hilson G, (2008) Fair trade gold: antecedents, prospects and challenges. Geoforum 39(1):386400

Hilson G, (2015) Fairtrade gold: antecedents, prospects and challenges. Geoforum 39(1): 386400

Jennings N, (1999) Social and labor issues in small-scale mines. Report for discussion at the Tripartite Meeting on Social and Labor Issues in Small-scale Mines. ILO, Geneva

Joy A \& Sherry JF (2003) Speaking of Art as Embodied Imagination: A Multisensory Approach to Understanding Aesthetic Experience. Journal of Consumer Research 30(2):259-282 doi: $\underline{10.1086 / 376802}$ 
Joy A, Sherry JF, \& Deschenes J (2009) Conceptual blending in advertising. Journal of Business Research 62(1): 39-49 doi: 10.1016/j.jbusres.2007.11.015

Kapferer JN \& Michaut-Denizeau A (2013) Is luxury compatible with sustainability? Luxury consumers' viewpoint. Journal of Brand. Management 21(1):1-22. doi: 10.1057/bm.2013.19

Keen M, (1998) Vertical Tax Externalities in the Theory of fiscal Federalism. IMF Economic Review 45: 454-485. doi: $10.2307 / 3867412$

Kempf M, (2017) Human Development through Fair Gold Mining? A case study of the Fair mined certification. Dissertation, Lund University.

Kjarsgaard BA \& Levinson AA (2002) Diamonds in Canada. Gems Gemology 38(3):208-238

Ki CW, Kwon TH „, \&Kim YW (2017) Luxury Fashion Consumers: Comparing High and Low Guilt Groups. Paper presented at the $2^{\text {nd }}$ Annual Conference Proceedings, International Textile and Apparel Association (ITAA)

Kyba M, Giuliani G, Franziskakis F, Tockner K, \& Lacroix P (2019) Artisanal and Small-Scale Mining Sites in the Democratic Republic of the Congo Are Not Associated with Nighttime Light Emissions. Multidisciplinary Scientific Journal 2(2):152-161. doi: 10.3390/j2020013

Lujala P, Gleditsch NP , \&Gilmore E (2205) A Diamond Curse? Civil War and a Lootable Resource. Journal of Conflict Resolution 49(4):538-562. doi: $10.1177 / 0022002705277548$

Moraes C, Carrigan M, Bosangit C, Ferreira C,\& McGrath M (2017) Understanding Ethical Luxury Consumption Through Practice Theories: A Study of Fine Jewellery Purchases. Journal of Business Ethics 145(3):525-543. doi:10.1007/s10551-015-2893-9

Muskawa K, (2014) Thematic lessons from the Marikana Miners' Strike in South Africa: A corporate governance perspective. Mediterranian Journal of Social Sciences 5(2): 63-67. doi: $\underline{10.5901 / \mathrm{mjss} .2014 \mathrm{v} 5 \mathrm{n} 2 \mathrm{p} 63}$

Okatei P, Cloutier C, \& Lehoux N (2017) Collaborative Mechanisms for Sustainable Supply Chain: A systematic Literature Review. Paper presented at CIRRETELT-2017-29, Université Laval, Québec, 14 ${ }^{\text {th }}$ June 2017. 
Reckwitz A, (2002) Toward a Theory of Social Practices: A Development in Culturalist Theorizing. European Journal of Social Theory 5(2): 243-263. doi: 10.1177/13684310222225432

Rettie R, Burchell K, \& Riley D (2012) Normalising green behaviours: A new approach to sustainability marketing. Journal of Marketing Manager 28(3-4): 420-444. doi:

10.1080/0267257X.2012.658840

Røpke I, (2009) Theories of practice - New inspiration for ecological economic studies on consumption. Ecological Economics 68(10): 2490-2497. doi: 10.1016/j.ecolecon.2009.05.015

Sanga G, (1997) The domestication of speech: toward a theory of glottology. Europaea 3(1):65120.

Sasso G., (2001) Ernesto De Martino fra religione e ilosoia. Bibliopolis, Napoli

Schatzki TR, (1997) Practices and Actions A Wittgensteinian Critique of Bourdieu and Giddens. Philosophy of the Social Science 27(3): 283-308. doi:10.1177/004839319702700301

Schatzki TR, (2001) Subject, Body, Place. Annals of the American Association of Geographers 91(4): 698-702. doi: 10.1111/0004-5608.00268

Schlosser K, (2013) Regimes of Ethical Value? Landscape, Race, and Representation in the Canadian Diamond Industry. Antipode 45(1):161-179. doi: 10.1111/j.1467-8330.2012.00996.X

Shove E \& Walker G (2010) Governing transitions in the sustainability of everyday life. Research Policy 39(4): 471-476. doi: 10.1016/j.respol.2010.01.019

Sippl K, (2015) Private and civil society governors of mercury pollution from artisanal and small-scale gold mining: A network analytic approach. The Extractive Industries and Society 2(2):198-208. doi: $10.1016 /$ j.exis.2015.01.008

Strahilevitz M \& Myers JG (1998) Donations to charity as purchase incentives: How well they work may depend on what you are trying to sell. Journal of Consumer Research 24(4):434-446

Strahilevitz M, (1999) The effects of product type and donation magnitude on willingness to pay more for a charity-linked brand. Journal of Consumer Psychology 8(3):215-241. doi: 10.1207/s15327663jcp0803_02

Tylor C., (1985) Philosophy and the Human Sciences. Cambridge University Press, Cambridge.

Valerio ,G (2013) Making trouble: Fighting for fair trade jewelry. Lion Books, Kidderminster 
van Maanen M, (2001) Phenomenology Course Handbook. Post-Workshop B. Ewha Women's University, Seoul.

Van Bockstael (2014) The persistence of informality: Perspectives on the future of artisanal mining in Liberia. Futures 62: 10-20. doi: 10.1016/j.futures.2014.02.004

Varadarajan PR, \& Menon A (1988) Cause-Related Marketing: A Coalignment of Marketing Strategy and Corporate Philanthropy. Journal of Marketing 52(3): 58-74. doi:

$\underline{10.1177 / 002224298805200306}$

Verbrugge B, (2017) Towards a negotiated solution to conflicts between large-scale and smallscale miners? The Acupan contract mining project in the Philippines. The Extractive Industries and Society $4(2): 352-360$. doi: $10.1016 /$ j.exis.2016.10.011

Warde A ,(2005) Consumption and Theories of Practice. Journal of Consumer Culture 5(2): 131153. doi: $\underline{10.1177 / 1469540505053090}$ 